\title{
Are research priorities in Latin America in line with the nutritional problems of the population?
}

\author{
Adolfo Llanos ${ }^{1,2, *}$, María Teresa Oyarzún ${ }^{1}$, Anabelle Bonvecchio ${ }^{3}$, Juan A Rivera ${ }^{3}$ \\ and Ricardo Uauy ${ }^{1,4}$ \\ ${ }^{1}$ Institute of Nutrition and Food Technology (INTA), Santiago, Chile: ${ }^{2}$ Arnot Ogden Medical Center, 600 Roe \\ Avenue, Elmyra, NY 14905, USA: ${ }^{3}$ National Institute of Public Health (INSP), Cuernavaca, Mexico: ${ }^{4}$ London \\ School of Hygiene and Tropical Medicine, London, UK
}

Submitted 24 October 2006: Accepted 22 June 2007: First published online 22 August 2007

\begin{abstract}
Objective: Concordance of nutritional research priorities with the related burden of disease is essential to develop cost-effective interventions to address the nutritional problems of populations. The present study aimed to evaluate whether nutrition research priorities are in agreement with the population's nutritional problems in Latin America.

Design: The epidemiological profile was contrasted with the research priorities and research produced by academic institutions for each country. Qualitative analysis of research production by type of contribution to problem solving was also conducted.

Settings: Nine Latin American countries.

Results: Obesity (high body mass index (BMI)) and micronutrient deficiencies (anaemia) emerged as key problems, followed by stunting, breast-feeding/ lactation and low birth weight. Wasting in children and women (low BMI) was uncommon. Concordance of ranked research priorities with the epidemiological profile of the country was generally good for nutrition-related chronic diseases, micronutrients and low birth weight, but not for undernutrition, stunting and breast-feeding. Studies on the efficacy and effectiveness of interventions were uncommon.

Conclusions: The present research agenda insufficiently supports the goal of public health nutrition, which is to ensure the implementation of cost-effective nutrition programmes and policies. A more rational approach to define research priorities is needed.
\end{abstract}

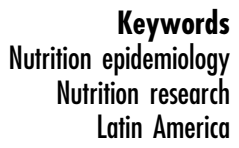

The alignment of research priorities with the corresponding population burden of disease is desirable to enhance the effectiveness and efficiency of actions required to improve health ${ }^{1-3}$. The magnitude and distribution of the main nutritional problems in the region should define and orient the health and nutrition research agenda of Latin America. Priority should be placed on risk factors that contribute most to the death and disability burden. The region faces a double burden of nutritional problems that affect health throughout the life course. Most countries have nutritional problems such as stunting, anaemia and micronutrient deficiencies (iron, zinc, vitamin A and folate), while concomitantly there is a progressive rise in obesity and nutrition-related chronic disease $(\mathrm{NRCD})^{4,5}$. The process of defining research priorities in most countries is mostly based on incentives to academic production based on impact factors of journal publications and often not in line with contributions to solving the region's health and nutrition problems. Funding opportunities are driven by factors other than the burden of death and disability of the most vulnerable groups in a region. The key opinion- and decision-makers are mostly concerned with the health demands of the most vocal groups in society, rather than with the underlying determinants of health and nutrition of the most vulnerable groups. Thus a significant share of nutrition research is aimed at solving problems with low population impact.

The Global Forum for Health Research's (GFHR) Child Nutrition Research Initiative ${ }^{6}$ funded a project conducted in nine countries of the Latin American region that aimed to develop a regional agenda for applied health and nutrition research based on existing epidemiological profiles. The main purpose of this work was the 
evaluation of the degree to which nutrition research priorities respond to the population's nutritional needs based on the burden of malnutrition in all its forms; this analysis comprises the main objective of the present paper. In addition, we examined the organised social responses to the identified nutrition problems (the existing policies and programmes), which will be the subject of a separate publication.

\section{Methods}

The project was developed jointly by the Institute of Nutrition and Food Technology (INTA, University of Chile) and the National Institute of Public Health (INSP, Mexico). Information on the nutritional status of the population and existing nutritional programmes, as well as research priorities, capabilities and scientific production, was gathered and analysed through interviews with key informants in academic institutions and research centres from nine Latin American countries: Brazil, Colombia, Costa Rica, Cuba, Chile, Guatemala, Mexico, Peru and Venezuela. Selection of participating countries was based on interest of existing national research institutes to participate in the project. We analysed the magnitude and distribution of the nutrition problems in these countries, and the research priorities as reported by the research institutions and as reflected by direct evidence from current research projects and publications. Additional detailed information on project methods and results is available at http://latinut.net by clicking on 'Foro Regional'.

The epidemiological profile of the nutrition situation for the nine participating countries was obtained from electronic searching of web pages of international organisations and from national sources, when available. Data were obtained from the World Health Organization (WHO)/Pan American health Organization (PAHO), United Nations Children's Fund, Food and Agriculture Organization of the United Nations, United Nations Development Programme and the World Bank, and sent to collaborators in each country for detailed review, updating when possible and verification. The main public nutritional problems for which information was generally available and therefore considered in the epidemiological profile were the following: low birth weight (LBW; $\leq 2500 \mathrm{~g}$ at birth), undernutrition in children (below -2 SD (standard deviations) of the median weight-for-height value of the National Center for Health Statistics (NCHS)/ WHO reference), stunting $(<-2 \mathrm{SD}$ of the median heightfor-age value of the NCHS/WHO reference), underweight in women (body mass index $(\mathrm{BMI})<18.5 \mathrm{~kg} \mathrm{~m}^{-2}$ ), anaemia prevalence in women and children (marker for iron and other deficiencies), vitamin A deficiency, overweight in women $\left(\mathrm{BMI}=25-29.9 \mathrm{~kg} \mathrm{~m}^{-2}\right)$, and obesity (BMI $\geq$ $30 \mathrm{~kg} \mathrm{~m}^{-2}$ ) in adults of either sex. An indicator on adequacy of breast-feeding (\% of children exclusively breast-fed to 4 months of age) was obtained from the WHO Global Data Bank on Breastfeeding and Complementary Feeding (http://www.who.int/research/iycf/ $\mathrm{bfcf} / \mathrm{bfcf}$.asp?menu $=00$ ). The epidemiological data were reviewed and completed by the country collaborator and then sent to regional experts for review. Information was presented according to the key public nutrition problems as listed. The group of experts established three severity categories (severe, moderate, mild or not significant) to rank the relevance of the nutritional problems (Table 1).

The project identified all organisations that carry out research in the area of nutrition and health; each was requested to complete a survey that included questions on type of institution, areas of interest, source of funding, institutional objectives and/or strategic plan, current main national and institutional research priorities, funded research projects, networking activities, outreach programmes, research productivity, publications and programmes.

The present paper reports on institutions that completed the survey and stated priorities and/or objectives related to nutrition and health research. However, since not all organisations responded, this paper is not truly representative of the universe of national research institutions. We also examined the publications and ongoing research projects reported as an objective expression of priorities. Of the 118 institutions completing the questionnaire, 56 were research institutions (20 in Brazil, nine in Mexico, six in Chile, five in Colombia, four in each of Guatemala and Peru, three in each of Venezuela and Costa Rica, and two in Cuba); the rest were unrelated to research.

Specific questions related to national and institutional research priorities were as follows: 'Describe the national research priorities in the field of health and nutrition; base your response in your knowledge of existing national priorities' (national priorities); and 'Has your institution established research priorities on the field of health and nutrition, and if so, please describe them' (institutional priorities). Both questions were left open to obtain the full spectrum of possibilities. Only the first three priorities listed were included in the analysis; each was assigned to a category of nutritional problems as described in Box 1. The not applicable category was used if the priority did not fit a specific category. Three categories - breastfeeding and lactation, food safety, and nutrition of the elderly - were added for completeness. The five major research projects recently completed or currently conducted were informed; and all publications in peerreviewed journals produced by the institution for 1999-2003 were listed.

Each research project and publication was classified based on the review of projects and publication titles. Articles where titles suggested a review paper, including meta-analysis and expert consensus, as well as book 
chapters were not included. Studies with similar titles published in different journals were considered as independent publications assuming they covered different aspects of the work. In the case of research projects or publications derived from collaboration between institutions, the work was considered for all institutions. The research projects and publications were grouped using two independent categories: one based on nutritional problems addressed, following the model used to classify priorities, and a second based on the nature of knowledge. The latter category intended to account for the type of knowledge produced by the research being conducted or the object of analysis (from cells to health systems). For example, research on basic science aspects of micronutrient deficiencies in contrast with the evaluation of nutritional interventions to solve micronutrient deficits; detailed information on the classification system used is presented in Box 2.

Stated national and institutional research priorities and priorities identified through projects were ranked within each country and for the overall group of countries using scores for national and institutional priorities and for research projects created within each category. The scores were obtained by dividing the frequency of responses for institutional and stated priorities and projects for each category provided by all institutions by the total number of potential responses. For example, in a country where 10 research institutions responded to the questionnaire, the number of potential responses would be 30 for each of institutional and national research priorities and 50 for projects. If five of the 10 institutions listed stunting as an institutional priority, then the score for stunting would be 0.50 . These scores served to rank priorities assigned to research for each category of nutritional problems. The final priority score was derived by adding up the scores assigned to each category in each country. Finally, on the basis of the scores, the problems were ranked from 1 to 9.

Analysis of congruence between research priorities and scientific production was conducted only for institutions that reported publications. The ranking for priorities based on publications was derived as follows: the number of publications in each category of the classifications by country was divided by the total number of publications in the country. A final summary score was also obtained for the nine countries by simply summing up the scores of a particular category for each country. Finally, on the basis of these scores, the categories of problems were ranked from 1 to 9. Comparison of congruence between stated research priorities, research production (including research projects and publications) and the epidemiological profile was conducted for breast-feeding, undernutrition, stunting, LBW, micronutrients and NRCD, comparing the rankings. Food safety and elderly nutrition were not included because there were no corresponding indicators in the epidemiological profile. 


\section{Box 1 - Categories of specific nutritional problems (research priorities, projects and publications)}

1. Undernutrition and its determinants: undernutrition, development or evaluation of growth (mainly weight-for-age) charts, diagnostic methods to assess the effect of nutrition on growth and development, assessment of energy expenditure in children and effect of infections (intestinal parasites, measles, pneumonia, infectious diarrhoea) on nutrition.

2. Low birth weight (LBW): studies that consider nutritional aspects during pregnancy, including assessment of intrauterine growth, and those involving nutrition of LBW and preterm infants.

3. Stunting (Stunt): studies related to causes and consequences of stunting in children.

4. Micronutrients: studies that refer to micronutrient deficiencies, independent of their possible linkage to other nutritional problems (i.e. studies on iron and LBW were classified as micronutrient).

5. Lactation and breast-feeding (BF): any study that relates to breast-feeding or lactation.

6. Obesity/nutrition-related chronic disease (NRCD): studies related to food habits, fat intake, lipid profiles, salt intake, oxidative stress and free radicals, functional foods (including pre- and probiotics), physical activity, lifestyle, dietary fibre, antioxidants, body fat composition, gestational diabetes, overweight, obesity, insulin resistance and components of the metabolic syndrome such as hypertension, cardiovascular disease, type II diabetes. Studies in children that evaluated nutritional risk factors for NRCD were also included in this category.

7. Food safety: research related to microbiological and chemical contamination of foods.

8. Nutrition of the elderly: studies that consider nutritional aspects of ageing individuals.

9. Not applicable for nutritional problems: publications that could not be categorised within the nutritional problems listed above. They include research involving pharmacological, physiological and clinical aspects of diseases unrelated to NRCD. For example, research on parenteral nutrition, inflammatory bowel diseases, metabolic diseases, alcoholism, AIDS, renal dialysis, lead poisoning, food allergies, nutritional topics in athletes, clinical series and case reports were among the more frequently cited.

Special cases include studies on $n-3$ and $n-6$ polyunsaturated fatty acids that were categorised within the LBW category if they were related to maternal and infant feeding and to NRCD if the population of reference were adults. Studies that evaluated methodologies to determine body composition in different population groups were included within the NRCD. Bone mineralisation studies were within the NRCD category if the study was related to changes in lifestyle including food habits and physical activity that may improve bone mineral content, and as micronutrients if the study addressed issues related to calcium and vitamin D deficiency. Studies that analysed nutrient content of food to improve nutrition were categorised within undernutrition if they evaluated protein and caloric content of food to prevent or treat undernutrition in children; or to NRCD if they evaluated caloric density, presence of fibre or lipid content, or dealt with oxidative stress related to NRCD in adults.

\section{Results}

The prevalence and public health significance of nutrition problems is presented in Table 2. The main form of malnutrition in the region is micronutrient deficiency, particularly anaemia in women and children and vitamin A deficiency in children. Anaemia prevalence was higher than $20 \%$ in children aged $<5$ years and higher than $25 \%$ in pregnant women in seven of eight countries studied. Marginal vitamin A deficiency was above $20 \%$ in three of seven countries. Overweight and obesity are among the leading nutrition problems in the region. Prevalences of obesity greater than $15 \%$ were found in four out of eight countries, and overweight prevalences in women were greater than $20 \%$ in all seven countries with information. The prevalence of wasting in children $<5$ years was low; less than 3\% and in most around 2\%. Even in women the prevalence of underweight appears to be low as sug- gested by the scarcity of data; only Brazil has prevalence higher than 5\%. Stunting ranked high, seven countries have prevalence greater than $6 \%$. Regarding LBW, eight of the nine studied countries have less than $10 \%$ with ranges from $5 \%$ in Chile to $13 \%$ in Guatemala. Peru (11\%), Brazil (10\%), Colombia and Mexico (9\%) present significant incidence of LBW. Venezuela is the country with the lowest rate of breast-feeding at 4 months of age (11\%), the other countries show rates from 34\% in Colombia to $73 \%$ for Peru. The result of the analysis of stated research priorities is shown in Table 3, panel A. National and institutional priorities related to nutritional problems were relatively similar based on the frequency they were reported and the resulting ranking (see bottom of Table 3). Undernutrition, NRCD and micronutrients ranked highest for both national and institutional priorities. The distributions of top national research priorities by country were as follows: undernutrition, Brazil, 


\section{Box 2 - Categories based on nature of knowledge applied to projects and publications}

1. Basic science studies: this category groups studies aimed at enhancing scientific knowledge needed to understand the effect of excess or deficit of nutrients on biological systems. Included in this category were basic science studies on metabolic and biochemical, cell biology and physiology, microbiology, cytogenetic and behavioural aspects; and clinical trials conducted in individuals to assess the role of nutrients in organ response and development.

2. Epidemiological studies: this category includes any descriptive or analytic, cohort or case-control studies designed to quantify any aspect of the nutritional problem in the population. We divide them in two categories:

- Nutritional surveillance studies: designed to measure the burden of the nutritional problem; to evaluate the magnitude and/or distribution of nutritional status and needs of the population; and to develop and/or test new biomarkers or indicators for the diagnosis of deficiencies or excess of nutrients.

- Risk factor assessment studies: designed to quantify the attributable risk of biological, cultural, socioeconomic and behavioural factors associated with the nutritional problem.

3. Clinical nutrition: applies to studies that evaluated treatment of diseases associated with the main nutritional problems, i.e. treatment of moderate to severe protein-energy malnutrition, iron-deficiency anaemia, complications related to overweight, hypertension, diabetes and cardiovascular diseases.

4. Nutrition intervention: studies that evaluate any aspect related to the efficacy of nutritional intervention, including establishing a regimen of administration, delivery of product to the community and compliance, as well as programme effectiveness when implemented in the community. Cluster randomised controlled studies, observational studies with controlled group, and time trend series designed to assess the efficacy of fortification and/or supplementation of nutrients.

5. Healtb promotion: studies that relate to nutrition education activities in promotion of nutritional aspects related to improving quality of life, physical activity and healthy food habits. Interventions aimed at promoting breast-feeding either in hospitals or in the community were included in this category.

6. Food technology: development of new food products or studies on food sciences. Development, quality control, safe storage and preservation of ingredients used for supplementation or fortification interventions.

7. Not applicable for nature of knowledge: publications that could not be classified in the categories described above.

Guatemala and Peru; food safety, Colombia and Costa Rica; NRCD, Cuba, Chile, Mexico and Costa Rica; micronutrients, Peru, Venezuela and Costa Rica.

The 56 institutions reported that 205 research projects were being conducted during the period 1999-2003, 185 (90\%) corresponded to key nutritional problems. Projects related to undernutrition (35\%), NRCD (25\%) and micronutrients (25\%) accounted for $85 \%$ of the total; while breast-feeding (4\%), LBW (4\%), elderly nutrition (3\%), stunting (2\%) and food security (1\%) lagged, totalling only $15 \%$ of all research projects. The breakdown of results by country is presented in Table 3. Consistency between the top national and institutional priorities within countries is observed in six of the nine counties (Brazil, Chile, Peru, Costa Rica, Cuba and Mexico). In three of them (Brazil, Chile and Peru) there is also consistency with the top priority problem addressed by research projects, and in another three countries (Costa Rica, Cuba and Mexico) consistency is observed among stated priorities and either the first or the second ranked research project. For Colombia, Guatemala and Venezuela consistency between national and institutional priorities was not found, but there was congruence between priority problems addressed by research projects and stated national or institutional priorities. Priorities that were categorised in the not applicable category were mentioned more frequently in the national compared with the institutional priority (fifth vs. seventh) and ranked in fourth place in research projects (see Table 3, panel A).

There were 974 original research articles in total during the five years considered. The publications provided by 20 of 56 research institutions that responded the questionnaire are shown in Table 4. A sizeable number of research articles, 307 of 974 (32\%), produced by regional nutrition research institutions were categorised as unrelated to the key nutritional problems identified. These publications corresponded to infection, pharmacology, toxicology or clinical sciences. Of the 666 publications categorised as related to key nutritional problems, 404 (61\%) were published in journals indexed in the MEDLINE database or MEDLINE publications indexed in LILACS (BIREME/PAHO/WHO). Comparison of priority ranking for institution with publications, shown in panel B of Table 3, shows close agreement between the institutions' stated priorities and the research conducted as reflected by research projects and publications in most of 
Table 2 Prevalence (\%) of nutrition problems by country, and ranking of public health significance based on criteria defined in Table 1

\begin{tabular}{|c|c|c|c|c|c|c|c|c|c|c|}
\hline \multirow[b]{2}{*}{ Country } & \multirow[b]{2}{*}{$\mathrm{BF}^{*}$} & \multicolumn{2}{|l|}{ Anaemiat } & \multirow[b]{2}{*}{$\begin{array}{c}\text { Vitamin A } \\
\text { deficiency } \ddagger \text { in } \\
\text { children }<3 \text { years }\end{array}$} & \multirow[b]{2}{*}{$\begin{array}{l}\text { Underweight women } \\
\left(\mathrm{BMl}<18.5 \mathrm{~kg} \mathrm{~m}^{-2}\right)\end{array}$} & \multirow[b]{2}{*}{$\begin{array}{l}\text { LBW infants } \\
(<2500 \mathrm{~g})\end{array}$} & \multirow[b]{2}{*}{$\begin{array}{l}\text { Wasting§ in } \\
\text { children } \\
<5 \text { years }\end{array}$} & \multirow[b]{2}{*}{$\begin{array}{l}\text { Stunting in } \\
\text { children } \\
<5 \text { years }\end{array}$} & \multirow[b]{2}{*}{$\begin{array}{c}\text { Women } 20-49 \text { years } \\
\text { with } \\
\mathrm{BMI}=25-29.9 \mathrm{~kg} \mathrm{~m}^{-2}\end{array}$} & \multirow[b]{2}{*}{$\begin{array}{l}\text { Obesity in adults } \\
\quad(\text { either sex) } \\
\left(\mathrm{BMl} \geq 30 \mathrm{~kg} \mathrm{~m}^{-2}\right)\end{array}$} \\
\hline & & Children $<5$ years & $\begin{array}{c}\text { Pregnant } \\
\text { women }\end{array}$ & & & & & & & \\
\hline Brazil & 40 & 48.0 & 12.0 & - & 6.2 & 10.0 & 2.3 & 10.5 & 25.6 & 9.9 \\
\hline Colombia & 34 & - & - & 23.3 & - & 9.0 & 0.8 & 13.5 & 31.6 & 9.6 \\
\hline Costa Rica & 63 & 21.6 & 27.9 & 8.7 ( $<6$ years $)$ & - & 7.0 & 2.3 & 6.1 & - & - \\
\hline Cuba & 44 & $\begin{array}{c}46.0 \\
(0.5-3 \text { years })\end{array}$ & 28.3 & 3.6 (0.5-2 years) & - & 6.0 & 2.0 & 4.6 & 25.3 (20-59 years) & 27.6 \\
\hline Chile & 72 & 19.0 & 25.0 & - & - & 5.0 & 0.3 & 1.5 & 40.0 & 38.7 \\
\hline Guatemala & 45 & 26 & 39.1 & 15.8 & 2.0 & 13.0 & 2.5 & 46.4 & 26.7 & 7.4 \\
\hline Mexico & 38 & 27.2 & 26.2 & 27.2 (<2 years) & 1.7 & 9.0 & 2.0 & 17.7 & 35.2 & 23.7 \\
\hline Peru & 73 & 27.8 & 61.4 & 13.1 & 0.7 & 11.0 & 0.9 & 25.4 & 36.6 & 14.6 \\
\hline Venezuela & 11 & 52 (<3 years) & 40.9 & 30.5 & - & 7.0 & 3.0 & 12.8 & - & 29.1 \\
\hline \multicolumn{11}{|c|}{ Number of countries (total of nine) based on public health significancell } \\
\hline High & 1 & 3 & 6 & 3 & 1 & 2 & - & 3 & 7 & 4 \\
\hline Medium & 8 & 5 & 2 & 2 & 1 & 5 & - & 4 & 0 & 4 \\
\hline Low or none & 0 & - & - & 2 & $2^{* *}$ & 2 & $9+t$ & $2 \ddagger \ddagger$ & 0 & 0 \\
\hline
\end{tabular}

$\mathrm{BF}$ - breast-feeding; BMI - body mass index; LBW - low birth weight.

* Percentage of children breast-fed at $<4$ months of age (data obtained from WHO Global Data Bank on Breastfeeding and Complementary Feeding).

+ Haemoglobin $<11 \mathrm{~g} \mathrm{dl}^{-1}$, adjusted by altitude.

$\ddagger$ Serum retinol $<20 \mathrm{mg} \mathrm{dl}^{-1}$.

§Underweight is defined as $<-2$ standard deviations of the weight-for-height median value of the National Center for Health Statistics (NCHS)/World Health Organization (WHO) reference data.

- Stunting is defined as $<-2$ standard deviations of the height-for-age median value of the NCHS/WHO reference data.

Based on severity categories described in the Methods section.

Both countries classified as no significant problem.

$+t$ Three countries classified as no significant problem.

\# Two countries classified as no significant problem. 
Table 3 Ranking of national and institutional research priorities, and research projects, by country: Panel A, all institutions; Panel B, institutions submitting a list of publications

\begin{tabular}{|c|c|c|c|c|c|c|c|c|c|c|c|c|}
\hline \multicolumn{13}{|l|}{ Panel A } \\
\hline \multirow[b]{2}{*}{ Country (no. of institutions) } & \multirow[b]{2}{*}{ Priority type } & \multicolumn{8}{|c|}{ Nutritional problems } & \multirow[b]{2}{*}{$\begin{array}{c}\text { Not } \\
\text { applicable }\end{array}$} & \multirow[b]{2}{*}{$\begin{array}{l}\text { No } \\
\text { response }\end{array}$} & \multirow[b]{2}{*}{$\begin{array}{l}\text { Potential } \\
\text { responses* }\end{array}$} \\
\hline & & Undernutrition & Stunt & LBW & Micronutrients & $\mathrm{BF}$ & NRCD & $\begin{array}{l}\text { Food } \\
\text { safety }\end{array}$ & $\begin{array}{l}\text { Elderly } \\
\text { nutrition }\end{array}$ & & & \\
\hline \multirow{3}{*}{ Brazil (20) } & National & $0.28 \ddagger$ & 0.02 & 0.02 & 0.16 & 0.02 & 0.1 & 0.05 & 0 & 0.02 & 0.37 & 60 \\
\hline & Institutional & $0.21 \ddagger$ & 0.03 & 0.02 & 0.18 & 0.02 & 0.18 & 0.03 & 0 & 0.03 & 0.28 & 60 \\
\hline & Research projects & $0.29 \ddagger$ & 0.03 & 0.02 & 0.18 & 0.03 & 0.1 & 0.01 & 0 & 0.1 & 0.34 & 100 \\
\hline \multirow[t]{3}{*}{ Colombia (5) } & National & 0.2 & 0 & 0 & 0.07 & 0.07 & 0.13 & 0.27 & 0 & 0 & 0.40 & 15 \\
\hline & Institutional & 0.33 & 0 & 0 & 0.13 & 0 & 0.33 & 0.2 & 0 & 0 & 0.00 & 15 \\
\hline & Research projects & 0.12 & 0 & 0 & 0.04 & 0 & 0.4 & 0 & 0 & 0.2 & 0.44 & 25 \\
\hline \multirow[t]{3}{*}{ Costa Rica (3) } & National & 0.11 & 0 & 0 & 0.22 & 0 & 0.22 & 0.22 & 0 & 0 & 0.22 & 9 \\
\hline & Institutional & 0 & 0 & 0 & 0.13 & 0 & 0.13 & 0 & 0 & 0 & 0.67 & 9 \\
\hline & Research projects & 0.33 & 0 & 0 & 0 & 0 & 0.2 & 0.07 & 0 & 0.2 & 0.40 & 15 \\
\hline \multirow[t]{3}{*}{ Cuba (2) } & National & 0 & 0 & 0 & 0.17 & 0 & 0.33 & 0.17 & 0 & 0 & 0.33 & 6 \\
\hline & Institutional & 0 & 0 & 0 & 0.17 & 0 & 0.33 & 0.17 & 0 & 0 & 0.33 & 6 \\
\hline & Research projects & 0 & 0 & 0 & 0.4 & 0 & 0.2 & 0 & 0.1 & 0 & 0.30 & 10 \\
\hline \multirow[t]{3}{*}{ Chile (6) } & National & 0 & 0 & 0 & 0.06 & 0 & 0.28 & 0 & 0.06 & 0 & 0.61 & 18 \\
\hline & Institutional & 0.11 & 0 & 0.06 & 0.11 & 0 & 0.39 & 0 & 0.11 & 0 & 0.22 & 18 \\
\hline & Research projects & 0.03 & 0 & 0.07 & 0.2 & 0 & 0.23 & 0.03 & 0.1 & 0.07 & 0.33 & 30 \\
\hline \multirow{3}{*}{ Guatemala (4) } & National & 0.25 & 0 & 0 & 0 & 0 & 0 & 0 & 0 & 0 & 0.75 & 12 \\
\hline & Institutional & 0.08 & 0 & 0.08 & 0.25 & 0 & 0.08 & 0 & 0 & 0.08 & 0.42 & 12 \\
\hline & Research projects & 0.5 & 0.05 & 0 & 0.1 & 0 & 0 & 0.05 & 0.05 & 0.05 & 0.25 & 20 \\
\hline \multirow[t]{3}{*}{ Mexico (9) } & National & 0.22 & 0 & 0 & 0.22 & 0 & 0.33 & 0 & 0 & 0.07 & 0.04 & 27 \\
\hline & Institutional & 0.15 & 0.04 & 0.04 & 0.11 & 0.04 & 0.22 & 0 & 0 & 0.04 & 0.37 & 27 \\
\hline & Research projects & 0.5 & 0.05 & 0 & 0.1 & 0 & 0 & 0.05 & 0.05 & 0.05 & 0.24 & 45 \\
\hline \multirow{3}{*}{ Peru (4) } & National & 0.33 & 0.08 & 0.08 & 0.33 & 0 & 0.08 & 0 & 0 & 0.08 & 0.00 & 12 \\
\hline & Institutional & 0.25 & 0 & 0.08 & 0.08 & 0.08 & 0 & 0 & 0 & 0 & 0.50 & 12 \\
\hline & Research projects & 0.3 & 0 & 0.05 & 0.15 & 0 & 0.1 & 0.05 & 0.05 & 0.15 & 0.30 & 20 \\
\hline \multirow{3}{*}{ Venezuela (3) } & National & 0.11 & 0 & & 0.22 & 0 & & 0 & & 0.33 & 0.33 & 9 \\
\hline & Institutional & 0.13 & 0 & & 0.13 & 0 & 0.25 & 0 & 0.13 & 0 & 0.44 & 9 \\
\hline & Research projects & 0.07 & 0 & 0.07 & 0.13 & 0 & 0.07 & 0 & 0.07 & 0.07 & 0.60 & 15 \\
\hline Summary† & National & 1.39 & 0.1 & 0.1 & 0.94 & 0.09 & 1.25 & 0.49 & 0.06 & 0.42 & 0.31 & 114 \\
\hline Ranking & National & 1 & $6-7$ & $6-7$ & 3 & 8 & 2 & 4 & 9 & 5 & & \\
\hline Summary† & Institutional & 0.69 & 0.07 & 0.22 & 1.18 & 0.02 & 1.66 & 0.4 & 0.24 & 0.11 & 0.29 & 114 \\
\hline Ranking & Institutional & 3 & 8 & 6 & 2 & 9 & 1 & 4 & 5 & 7 & & \\
\hline Summaryt & Research projects & 1.84 & 0.08 & 0.25 & 1.36 & 0.14 & 1.54 & 0.21 & 0.37 & 0.97 & 0.64 & 280 \\
\hline Ranking & Research projects & 1 & 9 & 6 & 3 & 8 & 2 & 7 & 5 & 4 & & \\
\hline
\end{tabular}


Table 3 Continued

Panel B

\begin{tabular}{|c|c|c|c|c|c|c|c|c|c|c|c|c|}
\hline \multirow[b]{2}{*}{ Country (no. of institutions) } & \multirow[b]{2}{*}{ Priority type } & \multicolumn{8}{|c|}{ Nutritional problems } & \multirow[b]{2}{*}{$\begin{array}{c}\text { Not } \\
\text { applicable }\end{array}$} & \multirow[b]{2}{*}{$\begin{array}{c}\text { No } \\
\text { response }\end{array}$} & \multirow[b]{2}{*}{$\begin{array}{l}\text { Potential } \\
\text { responses }\end{array}$} \\
\hline & & Undernutrition & Stunt & LBW & Micronutrients & $\mathrm{BF}$ & NRCD & $\begin{array}{l}\text { Food } \\
\text { safety }\end{array}$ & $\begin{array}{l}\text { Elderly } \\
\text { nutrition }\end{array}$ & & & \\
\hline \multirow[t]{3}{*}{ Brazil (3) } & Institutional & 0.221 & 0.02 & 0.02 & 0.18 & 0 & 0.16 & 0.02 & 0 & 0.04 & 0.56 & 9 \\
\hline & Research projects & 0.461 & 0.06 & 0 & 0 & 0 & 0.06 & 0 & 0 & 0.13 & 0.26 & 15 \\
\hline & Publication & 0.182 & 0.02 & 0.06 & 0.15 & 0.07 & 0.28 & 0.02 & 0.03 & 0.30 & & 250 \\
\hline \multirow{3}{*}{ Colombia (3) } & Institutional & 0.11 & 0 & 0 & 0.22 & 0 & 0.44 & 0 & 0 & 0.11 & 0.12 & 9 \\
\hline & Research projects & 0.06 & 0 & 0 & 0.06 & 0 & 0.4 & 0 & 0 & 0.2 & 0.26 & 15 \\
\hline & Publication & 0.33 & 0.05 & 0.05 & 0.14 & 0 & 0.21 & 0.10 & 0 & 0.12 & & 42 \\
\hline \multirow[t]{3}{*}{ Costa Rica (3) } & Institutional & 0 & 0 & 0 & 0.11 & 0 & 0.11 & 0 & 0 & 0.16 & 0.78 & $\begin{array}{r}42 \\
9\end{array}$ \\
\hline & Research projects & 0.33 & 0 & 0 & 0 & 0 & 0.2 & 0.06 & 0 & 0.2 & 0.2 & 15 \\
\hline & Publication & 0.06 & 0 & 0.05 & 0.25 & 0 & 0.49 & 0.09 & 0.02 & 0.06 & & 65 \\
\hline \multirow[t]{3}{*}{ Cuba (1) } & Institutional & 0 & 0 & 0 & 0.33 & 0 & 0.33 & 0.33 & 0 & 0 & 0.01 & 3 \\
\hline & Research projects & 0 & 0 & 0 & 0 & 0 & 0.8 & 0 & 0.2 & 0 & 0 & 5 \\
\hline & Publications & 0.08 & 0 & 0 & 0.25 & 0 & 0.67 & 0 & 0.25 & 0 & 0 & 12 \\
\hline \multirow[t]{3}{*}{ Chile (3) } & Institutional & 0.11 & 0 & 0 & 0.22 & 0 & 0.44 & 0 & 0 & 0.11 & 0.12 & 9 \\
\hline & Research projects & 0 & 0 & 0 & 0.4 & 0 & 0.2 & 0 & 0.06 & 0.06 & 0.26 & 15 \\
\hline & Publications & 0.06 & 0.02 & 0.05 & 0.13 & 0.03 & 0.29 & 0.01 & 0.02 & 0.44 & 0 & 413 \\
\hline \multirow[t]{3}{*}{ Guatemala (2) } & Institutional & 0.17 & 0 & 0.17 & 0.33 & 0 & 0.17 & 0 & 0 & 0 & 0.16 & 6 \\
\hline & Research projects & 0.7 & 0 & 0 & 0 & 0 & 0 & 0.1 & 0.1 & 0.1 & 0 & 10 \\
\hline & Publications & 0.20 & 0 & 0.03 & 0.26 & 0 & 0.26 & 0 & 0.00 & 0.26 & 0 & 35 \\
\hline \multirow[t]{3}{*}{ Mexico (5) } & Institutional & 0.07 & 0.07 & 0.07 & 0.13 & 0.07 & 0.13 & 0 & 0 & 0.07 & 0.39 & 15 \\
\hline & Research projects & 0.24 & 0 & 0 & 0.16 & 0.12 & 0.28 & 0 & 0 & 0.16 & 0.04 & 25 \\
\hline & Publications & 0.31 & 0.03 & 0.03 & 0.21 & 0.09 & 0.15 & 0 & 0.02 & 0.28 & & 107 \\
\hline \multirow{3}{*}{ Peru (2) } & Institutional & 0.5 & 0 & 0.17 & 0.17 & 0.17 & 0 & 0 & 0 & 0 & 0 & 6 \\
\hline & Research projects & 0.4 & 0 & 0.1 & 0.3 & 0 & 0.1 & 0 & 0 & 0.1 & 0 & 10 \\
\hline & Publications & 0.48 & 0 & 0.06 & 0.36 & 0.06 & 0.03 & 0.03 & 0 & 0.03 & 0 & 33 \\
\hline \multirow[t]{3}{*}{ Venezuela (1) } & Institutional & 0 & 0 & 0 & 0 & 0 & 0 & 0 & 0 & 0 & 1 & 3 \\
\hline & Research projects & 0.2 & 0 & 0.2 & 0.2 & 0 & 0 & 0 & 0 & 0.2 & 0.2 & 5 \\
\hline & Publications & 0.48 & 0 & 0.06 & 0.36 & 0.06 & 0.03 & 0.03 & 0 & 0.03 & 0.4 & 16 \\
\hline Summaryt & Institutional & 0.96 & 0.09 & 0.43 & 1.69 & 0.24 & 1.78 & 0.35 & 0 & 0.33 & 3.14 & 69 \\
\hline Ranking & Institutional & 3 & 8 & 4 & 2 & 7 & 1 & 5 & 9 & 6 & 0 & 0 \\
\hline Summaryt & Research projects & 1.93 & 0.06 & 0.30 & 1.12 & 0.12 & 2.04 & 0.16 & 0.36 & 1.15 & 1.22 & 115 \\
\hline Ranking & Research projects & 2 & 9 & 6 & 4 & 8 & 1 & 7.10 & 5 & 3 & & \\
\hline Summaryt & Publications & 2.01 & 0.11 & 0.38 & 2.11 & 0.31 & 2.41 & 0.28 & 0.34 & 1.52 & 0 & 973 \\
\hline Ranking & Publications & 2 & 9 & 5 & 3 & 7 & 1 & 8 & 6 & 4 & 0 & 0 \\
\hline
\end{tabular}

Stunt - stunting; LBW - low birth weight; BF - breast-feeding; NRCD - nutrition-related chronic disease.

Potential responses derived from a maximum of three priorities, five research projects and all publications sent by institutions in each country.

+ Value resulting from the sum of proportion assigned to each nutritional problem per type of priority for all countries.

$\ddagger$ Proportion derived from the number of responses assigned to each category of nutritional problem relative to the potential responses per type of priority in each country. 
the categories. This is the case for NRCD which ranked first across the three priority classes; undernutrition and micronutrient deficiencies ranked third and second in the institutional priority listing, respectively. The qualitative analysis in relation to the nature of scientific knowledge is shown in Table 5. Most research projects and publications belong to basic scientific and epidemiological evaluations (nutritional survey and risk factors), accounting for up to $64 \%$ and $69 \%$ of all research project and publications, respectively. Nutrition interventions and health promotion account for $27 \%$ of research projects and $16 \%$ of publications, respectively. The analysis by specific category showed that micronutrients accounted for $44 \%$ of all

Table 4 Publications by institution and country and according to classification as priority or non-priority nutrition problems

\begin{tabular}{lcc}
\hline $\begin{array}{l}\text { Country (no. of } \\
\text { institutions) }\end{array}$ & $\begin{array}{c}\text { Priority nutritional } \\
\text { problems, } n(\%)\end{array}$ & $\begin{array}{c}\text { Total publications, } \\
n(\%)\end{array}$ \\
\hline Brazil (3) & $175(70)$ & $250(26)$ \\
Chile (3) & $232(56)$ & $413(42)$ \\
Colombia (3) & $37(88)$ & $42(4)$ \\
Costa Rica (4) & $61(92)$ & $66(7)$ \\
Cuba (1) & $12(100)$ & $12(1)$ \\
Guatemala (2) & $26(74)$ & $35(4)$ \\
Mexico (5) & $77(72)$ & $107(11)$ \\
Peru (2) & $32(97)$ & $33(3)$ \\
Venezuela (1) & $14(88)$ & $16(2)$ \\
Total & $666(68)$ & 974 \\
\hline
\end{tabular}

research projects and $17 \%$ of the publications are related to nutrition interventions, whereas the NRCD category accounts for only $4 \%$ of the research projects and $1 \%$ of all publications. In summary, most research conducted on nutrition problems is aimed at generating knowledge in understanding the effects of excess and deficit of nutrients, assessing the burden of disease, and the evaluation of risk factors, but not to address the implementation and evaluation of nutrition interventions in promoting health.

The analysis of concordance between institutional priorities and research production with the public health significance of the key nutritional problems, based on the epidemiological profile, is presented in Table 6. For all institutions there is relatively good agreement between the epidemiological profile of the country and the institutional research priorities on the basis of research projects for NRCD, LBW and micronutrients, but not for undernutrition, stunting and breast-feeding.

\section{Discussion}

The GFHR project conducted in nine Latin American countries has served its purpose in providing a critical analysis of the scientific standing of research institutions in the region and can be used to judge whether the key nutritional problems based on the epidemiology are

Table 5 Distribution of research projects and publications by nutritional problem and nature of scientific knowledge

\begin{tabular}{|c|c|c|c|c|c|c|c|c|c|c|c|c|c|c|c|c|c|c|}
\hline \multirow{3}{*}{$\begin{array}{l}\text { Nature of scientific } \\
\text { knowledge }\end{array}$} & \multicolumn{16}{|c|}{ Main nutritional problems } & & \\
\hline & \multicolumn{2}{|c|}{ Undernutrition } & \multicolumn{2}{|c|}{ Stunt } & \multicolumn{2}{|c|}{ LBW } & \multicolumn{2}{|c|}{ Micronutrients } & \multicolumn{2}{|c|}{$\mathrm{BF}$} & \multicolumn{2}{|c|}{ NRCD } & \multicolumn{2}{|c|}{ Food safety } & \multicolumn{2}{|c|}{ Elderly nutrition } & \multicolumn{2}{|c|}{ Total } \\
\hline & $n$ & $\%$ & $n$ & $\%$ & $n$ & $\%$ & $n$ & $\%$ & $n$ & $\%$ & $n$ & $\%$ & $n$ & $\%$ & $n$ & $\%$ & $n$ & $\%$ \\
\hline \multicolumn{19}{|l|}{ Basic science } \\
\hline Research projects & 12 & 19 & 2 & 50 & 3 & 38 & 9 & 21 & 5 & 63 & 7 & 15 & 1 & 20 & 5 & 14 & 40 & 22 \\
\hline Publications & 20 & 13 & 2 & 11 & 12 & 26 & 61 & 38 & 8 & 20 & 82 & 31 & 4 & 19 & 8 & 38 & 181 & 27 \\
\hline \multicolumn{19}{|l|}{ Clinical nutrition } \\
\hline Research projects & 2 & 3 & & 0 & 0 & 0 & 0 & 0 & 0 & 0 & 1 & 2 & 0 & 0 & 0 & 0 & 3 & 2 \\
\hline Publications & $1 \overline{4}$ & 10 & 0 & 0 & 6 & 13 & 15 & 9 & 5 & 12 & 11 & 4 & 1 & 5 & 5 & 21 & 47 & 7 \\
\hline \multicolumn{19}{|l|}{ Nutritional survey } \\
\hline Research projects & 15 & 23 & 1 & 25 & 2 & 25 & 11 & 26 & 0 & 0 & 4 & 9 & 0 & 0 & 0 & 71 & 38 & 21 \\
\hline Publications & 46 & 30 & 11 & 58 & 12 & 26 & 43 & 27 & 10 & 24 & 63 & 24 & 1 & 5 & 10 & 29 & 176 & 26 \\
\hline \multicolumn{19}{|l|}{ Risk factor assessment } \\
\hline Research projects & 11 & 17 & 1 & 25 & 1 & 13 & 1 & 2 & 2 & 25 & 21 & 46 & 1 & 20 & 2 & 0 & 38 & 21 \\
\hline Publications & 26 & 17 & 4 & 21 & 12 & 26 & 5 & 3 & 8 & 20 & 53 & 20 & 8 & 38 & 8 & 4 & 108 & 16 \\
\hline \multicolumn{19}{|l|}{ Nutritional interventions } \\
\hline Research projects & 8 & 13 & 0 & 0 & 2 & 25 & 19 & 44 & 1 & 13 & 2 & 4 & 0 & 0 & 1 & 0 & 32 & 17 \\
\hline Publications & 17 & 11 & 1 & 5 & 2 & 4 & 28 & 17 & 5 & 12 & 2 & 1 & 0 & 0 & 5 & 4 & 50 & 8 \\
\hline \multicolumn{19}{|l|}{ Health promotion } \\
\hline Research projects & 8 & 13 & 0 & 0 & 0 & 0 & 0 & 0 & 0 & 0 & 9 & 20 & 1 & 20 & 0 & 0 & 18 & 10 \\
\hline Publications & 13 & 8 & 1 & 5 & 2 & 4 & 3 & 2 & 5 & 12 & 35 & 13 & 1 & 5 & 5 & 4 & 55 & 8 \\
\hline \multicolumn{19}{|l|}{ Food technology } \\
\hline Research projects & 8 & 13 & 0 & 0 & 0 & 0 & 3 & 7 & 0 & 0 & 2 & 4 & 2 & 40 & 0 & 14 & 16 & 9 \\
\hline Publications & 15 & 10 & 0 & 0 & 0 & 0 & 6 & 4 & 0 & 0 & 17 & 6 & 6 & 29 & 0 & 0 & 44 & 7 \\
\hline \multicolumn{19}{|l|}{ Not applicable } \\
\hline Research projects & 0 & 0 & 0 & 0 & 0 & 0 & 0 & 0 & 0 & 0 & 0 & 0 & 0 & 0 & 0 & 0 & 0 & 0 \\
\hline Publications & 3 & 2 & 0 & 0 & 1 & 2 & 0 & 0 & 0 & 0 & 1 & 0 & 0 & 0 & 0 & 0 & 5 & 1 \\
\hline \multicolumn{19}{|l|}{ Total } \\
\hline Research projects & 64 & $35^{*}$ & 4 & 2 & 8 & 4 & 43 & 23 & 46 & 25 & 5 & 3 & 8 & 4 & 7 & 4 & 185 & 100 \\
\hline Publications & 154 & $23+$ & 19 & 3 & 47 & 7 & 161 & 24 & 264 & 40 & 21 & 3 & 41 & 6 & 24 & 4 & 666 & 100 \\
\hline
\end{tabular}

* Proportion relative to total number of research projects.

†Proportion relative to total number of publications. 
Table 6 Ranking of research priorities according to prevalence (epidemiological data), stated institutional priorities and publications on key nutritional problems

\begin{tabular}{|c|c|c|c|c|c|c|}
\hline Priorities & $\mathrm{BF}$ & Undernutrition & Stunt & LBW & Micronutrients & NRCD \\
\hline Epidemiology* & 4 & 6 & 3 & 5 & 1 & 2 \\
\hline \multicolumn{7}{|c|}{ All analysed institutions $(n=56)$} \\
\hline Institutionalt & 6 & 3 & 5 & 4 & 2 & 1 \\
\hline Research projects & 5 & 1 & 6 & 4 & 3 & 2 \\
\hline \multicolumn{7}{|c|}{ Institutions with publications $(n=24) \ddagger$} \\
\hline Institutional & 5 & 3 & 6 & 4 & 2 & 1 \\
\hline Research projects & 5 & 2 & 6 & 4 & 3 & 1 \\
\hline Publications & 6 & 2 & 5 & 4 & 3 & 1 \\
\hline
\end{tabular}

BF - breast-feeding; Stunt - stunting; LBW - low birth weight; NRCD - nutrition-related chronic disease.

${ }^{*}$ Ranking based on the number of countries within the severe category for key nutritional problems.

t Ranking derived from the final score summary for key nutritional problems (food safety and elderly nutrition excluded) presented in Table 3 , Panel A.

$\ddagger$ Ranking derived from the final score summary for key nutritional problems (food safety and elderly nutrition excluded) presented in Table 3 , Panel B.

being addressed by the research agenda. We further developed a semi-quantitative assessment method that served to rank research priorities, current projects and recent publications from the nine countries and compared these with the epidemiological profile. Thus, the degree of concordance of the research agenda (priorities, projects, publications) with the epidemiological profile was verified. Finally, we conducted qualitative analysis of research production in terms of the type of knowledge provided to enhance public health nutrition action in the region. The results show that self-reported institutional and national stated priorities, and research products as represented by current projects and publications, compared reasonably well with the ranking of nutritional problems based on the epidemiological profile. The concordance was stronger for NRCD, micronutrient deficiencies and LBW; there was less agreement for stunting, breast-feeding and undernutrition.

We also assessed the nature of the research being conducted based on projects and publications. This analysis revealed that the purpose of most studies was the evaluation of nutritional status and risk factors for nutritional problems, or considerations of what needs to be done. Very little work, if any, was related to how interventions need to be conducted to ensure efficacy and effectiveness at the population level. Virtually no work was focused on evaluation of the cost-effectiveness of programmes. Thus, the existing research approaches are inadequate to support the goal of public health nutrition, which is to ensure the implementation of the most costeffective nutrition interventions and health policies. We think that, despite the limitations in the methods used to evaluate the relevance to public health of research in nutrition in the region, the work presented in this paper serves to highlight the need to define a more rational approach to setting research priorities.

The analysis of the epidemiological profile is in agreement with the existence of a double burden of nutrition-related disease (undernutrition and micro- nutrient deficits coexisting with NRCD) faced by most developing countries undergoing the nutrition transi$\operatorname{tion}^{4,5,7}$. The comparative analysis of the epidemiological ranking with the national and institutional priorities related to key nutritional problems revealed good agreement in the case of micronutrients and NRCD. Stunting and breast-feeding, despite their importance as significant nutritional problems in the region, have been neglected if judged by the analysis of priority setting and research products. This contrasts with the importance that has been placed by the institutions on activities related to malnutrition control and prevention; these ranked in the three top national and institutional priorities as well as in research projects, despite the fact that protein-energy malnutrition is no longer a prevalent nutrition problem affecting the region. The analysis of the subgroup of institutions with publications showed similar discrepancies. The fact that breast-feeding is not stated as a top nutritional priority and not reflected in the research products was somehow unexpected based on a recent analysis that suggested increasing interest in breastfeeding research within Latin America ${ }^{8}$.

The possible explanation for the discrepancies between the epidemiological profile, stated priorities and research publications in areas such as stunting and breastfeeding may be related to the gap in the expertise of research groups to address particular topics. This has a built-in inertia, i.e. research groups continue to work on topics long after they become less relevant. Experts in a given topic have a relative advantage in obtaining funds and in publishing their research products in peerreviewed journals; this may be a significant contributor to the present gap between current problems and recent publications. Furthermore, research institutions have difficulties in securing staff development programmes to update skills and knowledge. In addition, novel methods may be needed to address new problems or a changing scenario; resources are often not available and institutional policies do not favour changing the status quo. 
Government-funded research and donors are commonly enticed to support what is being offered by the existing research groups rather than demand what is needed to solve current population nutrition problems. Academic staff members at universities and research centres in the region are commonly tenured from the earliest stages of their career, thus making the imperative to update institutional research skills less urgent.

The analysis of the not applicable category offered critical information to judge the presence of the 10/90 gap in topics that are not related to key nutritional problems. Not applicable research projects rank fourth whereas institutional priorities rank seventh. A similar pattern was observed for the subgroup of institutions with publications in the ranking analysis of all institutions; the not applicable category ranked third and fourth for research projects and publications and sixth for institutional priorities. The relatively higher importance of the not applicable category in research productivity is not in agreement with institutional priorities, suggesting that there are greater funding opportunities for topics that are not public health priorities for the region. This may be the reflection of the thesis proposed by the 10/90 gap, i.e. that research being conducted in developing countries often serves the interests of industrialised countries ${ }^{1}$. An additional explanation may be the existence of a different type of 10/90 gap than the one traditionally defined by the GFHR; this gap may reflect the strong influence that groups with greater socio-economic status and political power have in defining the research agenda.

Our characterisation of the research projects and publications by the nature of the knowledge provided illustrates the limited capacity of institutions to respond to the research needs of their populations. Studies addressing basic research questions and epidemiological assessments account for close to $60 \%$ of evaluated research projects and publications. Studies evaluating the effectiveness of nutritional intervention and health promotion activities, which have greater potential impact on the definition of public nutrition policies, fall behind with less than a third of all research projects. Food technology, an area useful for the development of foods with nutritional or functional attributes aimed at reducing malnutrition, is also poorly represented with less than 10\%. The workshop held by the United Nations University (UNU) and the International Union of Nutritional Sciences (IUNS) in Manila identified the lack of adequate facilities and appropriately trained professionals, which is responsible for the limited capacity of institutions to respond to the research needs of their populations, as a key barrier for effective nutrition programmes ${ }^{9}$. Nutritionists are not well-equipped with the skills, knowledge and attitudes required to become more solution-oriented and less discipline-focused.

However, the results of this analysis should be examined with caution. First, the lack of information from other countries in the region and the incomplete responses from the institutions identified limit the generalisability of the analysis. Second, the epidemiological profiles are intended to reflect the national average, and thus are not necessarily representative of the distribution of the nutritional problem within special groups or of the disparities existing by geographic region. Third, the institutional research priorities reflect what is stated, not what is actually carried out. The comparison of priorities with ongoing research projects and with publications provides a more accurate representation of the real priorities of the institutions. Fourth, the method used for the classification of ongoing projects and publications into priority topics and nature of knowledge was based only on the titles of the publications and not on their content. Fifth, there is limited generalisability of the results of the analysis conducted in institutions with publications, especially for Brazil and Venezuela, where less than $50 \%$ of the institutions sent their list of publications. Despite the limitations, the results of this analysis offered valuable information to analyse the existence of a 10/90 gap but most importantly to highlight the limited capacity of research institutions to generate research that evaluates the efficacy and effectiveness of interventions. The UNU/IUNS and other professional/ academic networks have delineated different lines of action to effectively build capacity that involves changing the focus of research and training, re-examining existing funding priorities, defining the impact factor of research publications, and re-assessing career advancement and promotion criteria to reward solution-oriented research. Most countries in the region are at different stages of the demographic/health/nutrition transition with varying combinations of deficiency disease and a rapid emergence of NRCD. There are major disparities in the prevalence of diseases within and between countries which make generalisations in description, analysis and programmatic action especially difficult. Thus it is best to interpret the information as indicative of different realities within the region rather than as a compelling summary representation of what the real situation is. This can best be accomplished considering by sub-regions within countries or regions that cross national boundaries.

\section{Acknowledgements}

Sources of funding: The study was funded by the Child Health and Nutrition Research Initiative of the Global Forum for Health Research.

Conflict of interest declaration: None.

Authorship responsibilities: R.U. and J.A.R. are principal investigators of the GFHR project. A.L., M.T.O. and A.B. are co-investigators in the same project. All co-authors contributed in writing of this paper. R.U. is the guarantor. 


\section{References}

1 Global Forum for Health Research (GFHR). 10/90 Report on Health Research 2003-2004. Report No. 4. Geneva: GFRH, 10 May 2004

2 World Health Organization (WHO). Macroeconomics and Health: Investing in Health for Economic Development. Report of the Commission on Macroeconomics and Health. Geneva: WHO, 2001.

3 Bloom BR, Michaud CM, La Montagne JR, Simonsen L. Priorities for global research and development of interventions. In: Jamison DT, Breman JG, Measham AR, Alleyne G, Claeson M, Evans DB, et al., eds. Disease Control Priorities in Developing Countries, 2nd ed. Washington, DC: The World Bank and Oxford University Press, 2006; 103-18.

4 Freire WB, ed. Nutrition and an Active Life: From Knowledge to Action. Scientific and Technical Publication No. 612. Washington, DC: Pan American Health Organization, 2005.

5 World Health Organization (WHO). Report of the Joint WHO/FAO Expert Consultation on Diet, Nutrition and the
Prevention of Chronic Diseases. Technical Report Series No. 916. Geneva: WHO, 2003.

6 Child Health and Nutrition Research Initiative. The 10/90 Report on Health Research 2001-2002. Geneva: Global Forum for Health Research, 2006; 181-7.

7 Mendez MA, Monteiro CA, Popkin BM. Overweight exceeds underweight among women in most developing countries. American Journal of Clinical Nutrition 2005; 81(3): 714-21.

8 Victora C, Albernaz E, Lutter C. The role of research in the formulation of infant feeding. In: Freire WB, ed. Nutrition and an Active Life: From Knowledge to Action. Scientific and Technical Publication No. 612. Washington, DC: Pan American Health Organization, 2005; 21-32.

9 Institution Building for Research and Advanced Training in Food and Nutrition in Developing Countries, based on a Workshop held by the United Nations University and the International Union of Nutritional Sciences in Manila, Philippines, 18-23 August 1996 [special issue]. Food and Nutrition Bulletin 1997; 18(2). 